\title{
Icariin reduces high glucose-induced endothelial progenitor cell dysfunction via inhibiting the p38/CREB pathway and activating the Akt/eNOS/NO pathway
}

\author{
SISI CHEN ${ }^{1-3}$, ZHENYA WANG ${ }^{1-3}$, HENG ZHOU ${ }^{1-3}$, \\ BO $\mathrm{HE}^{1-3}, \mathrm{DAN} \mathrm{HU}^{1-3}$ and HONG JIANG ${ }^{1-3}$ \\ ${ }^{1}$ Department of Cardiology, Renmin Hospital of Wuhan University; ${ }^{2}$ Cardiovascular Research Institute, Wuhan University; \\ ${ }^{3}$ Hubei Key Laboratory of Cardiology, Wuhan, Hubei 430060, P.R. China
}

Received December 25, 2018; Accepted September 4, 2019

DOI: 10.3892/etm.2019.8132

\begin{abstract}
High glucose (HG) impairs endothelial progenitor cell (EPC) function. The activation of p38 mitogen-activated protein kinase and the inhibition of the Akt/eNOS/NO pathway serve central roles in this process. Icariin has protective effects in endothelial cells. The aim of the present study was to investigate the effects of icariin on HG-induced EPC dysfunction, including proliferation, migration and tube formation. Experiments were performed with EPCs isolated from the femurs and tibias of Sprague-Dawley rats in vitro. In a dose-dependent manner, icariin reversed the inhibition of EPC proliferation induced by $\mathrm{HG}$ treatment, and the maximal effective concentration of icariin was $1 \mu \mathrm{M}$ [Fold change (FC):0.90 $\pm 0.07, \mathrm{P}=0.0124$ vs. HG group]. The impaired EPC migration and tube formation induced by glucose was partially restored by $1 \mu \mathrm{M}$ icariin treatment (FC: $0.81 \pm 0.08, \mathrm{P}=0.0148$ vs. HG group for migration; $0.82 \pm 0.03, \mathrm{P}=0.0214$ vs. HG group for tube formation). Furthermore, icariin significantly suppressed HG-induced p38 and cAMP response element binding protein (CREB) phosphorylation in EPCs (FC: $1.84 \pm 0.21, \mathrm{P}=0.0238$ vs. $\mathrm{HG}$ group for p38; FC: $2.24 \pm 0.15$, $\mathrm{P}=0.0068$ vs. $\mathrm{HG}$ group for $\mathrm{CREB}$ ). Increased Akt and endothelial nitric oxide (NO) synthase (eNOS) activation was also observed after icariin treatment (FC: $0.64 \pm 0.08, \mathrm{P}=0.0047$ vs. $\mathrm{HG}$ group for Akt; FC:0.53 $\pm 0.05, \mathrm{P}=0.0019$ vs. HG group for eNOS), which was followed by increased NO production (FC: $0.69 \pm 0.06, \mathrm{P}=0.0064$ vs. HG group). In conclusion, icariin attenuated HG-induced EPC dysfunction, which may be
\end{abstract}

Correspondence to: Professor Hong Jiang, Department of Cardiology, Renmin Hospital of Wuhan University, 238 Jiefang Road, Wuchang, Wuhan, Hubei 430060, P.R. China

E-mail: whujianghong@163.com

Key words: icariin, endothelial progenitor cell, proliferation, migration, tube formation partially attributed to the inhibition of the $\mathrm{p} 38 / \mathrm{CREB}$ pathway and the activation of the Akt/eNOS/NO pathway. Icariin may be a therapeutic candidate for improving the function of EPC.

\section{Introduction}

Endothelial progenitor cells (EPCs), derived from bone marrow or peripheral blood cells, have been shown to be incorporated into the foci of physiological and pathological neovascularization (1). EPCs can home to sites of ischemia, differentiate into endothelial cells and can contribute to postnatal neovascular formation (2). The beneficial angiogenic properties of EPC for cell therapy have attracted the attention of numerous researchers $(3,4)$; however, the initial clinical use of EPCs has not yielded the predicted positive outcomes (5). One of the reasons is that patients with coronary artery disease (CAD) already possess risk factors, such as diabetes, hypertension and smoking, which could reduce EPC number and impair EPC migration (6). EPCs isolated from patients with type I or type II diabetes exhibited impaired proliferation, adhesion and incorporation into vascular structures (7). High glucose (HG) also impairs the number and function of EPCs $(8,9)$. The mechanism of HG-induced EPC impairment is related to the activation of the $\mathrm{p} 38$ mitogen-activated protein kinase (MAPK) pathway (10). Additionally, a number of studies have shown that HG could reduce EPC proliferation and migration by exerting a deleterious effect on the PI3K/Akt/endothelial nitric oxide (NO) synthase (eNOS) signaling cascade $(11,12)$.

Icariin $\left(\mathrm{C}_{33} \mathrm{H}_{40} \mathrm{O}_{15}\right.$; molecular weight, 676.66), a flavonoid extracted from several plants in the genus Epimedium, exhibits various pharmacological activities, including enhancing immune function, stimulating osteoblast proliferation, antioxidative stress, antiapoptosis, stimulation of angiogenesis and improving cardiovascular function (13-16). Icariin has been shown to protect against endothelial cell dysfunction by activating eNOS and increasing NO production (17). However, the role of icariin in HG-induced EPC dysfunction is yet to be elucidated. In the present study, it was hypothesized that the administration of icariin could reduce glucose-induced EPC dysfunction. 


\section{Materials and methods}

Cell culture and icariin treatment. Male Sprague Dawley (SD) wild-type rats (SPF grade; 180-200 g; 2-3 weeks; n=3) were obtained from Wuhan University Experiment Animal Center. These rats were allowed free access to standard rat chow and water, and were kept in an environment with controlled temperature and lighting $\left(24^{\circ} \mathrm{C} ; 12 / 12\right.$ h-light/dark cycle; humidity, $50-60 \%)$. Mononuclear cells were isolated from bone marrow from the femurs and tibias of SD rats, and cultured in endothelial basal medium (EBM-2 SingleQuots; Lonza Group, Ltd.) containing 5\% FBS, human vascular endothelial growth factor A, human fibroblast growth factor-2, human epidermal growth factor, insulin-like growth factor-1 and ascorbic acid (EBM-2 SingleQuots; Lonza Group, Ltd.) to induce mononuclear cells differentiation into EPCs at $37^{\circ} \mathrm{C}$ in an atmosphere containing 95\% air and $5 \% \mathrm{CO}_{2}$. After 3 days in culture, the non-adherent cells were removed, and the adherent cells were maintained in new media. EPCs were characterized by FITC-Ulex europaeus agglutinin I (cat. no. L9006; Sigma-Aldrich; Merck KGaA) and DiI-acetylated low-density lipoprotein (cat. no. H7970; Beijing Solarbio Science \& Technology Co., Ltd.) as previously described (18). Icariin ( $\geq 94 \%$ purity as determined by high-performance liquid chromatography analysis by the supplier) was purchased from Sigma-Aldrich (Merck KGaA) and dissolved in dimethyl sulfoxide at a concentration of $10 \mathrm{mmol} / \mathrm{l}$ for storage. The cytotoxicity of icariin toward EPC was evaluated using a cell viability assay. Following incubation of EPCs with icariin $(0.01,0.1$ or $1 \mu \mathrm{M})$, cells were exposed to $0.4 \%$ trypan blue solution (cat. no. T6146; Sigma-Aldrich; Merck KGaA) for 5 min and viewed under a light microscope (magnification, x100). Cell viability was defined as the ratio of unstained cells to the total number of cells. The EPCs were cultured in $5.5 \mathrm{mM}$ glucose (Control group) or $25 \mathrm{mM}$ glucose (HG group) for 3 days at $37^{\circ} \mathrm{C}$ and used for subsequent experiments (19). In the proliferation assay, the cells were cultured in serum-free EBM-2 for $12 \mathrm{~h}$ for synchronization and then treated with or without icariin $(0.01$, 0.1 or $1 \mu \mathrm{M}$ ) under a high glucose condition for $24 \mathrm{~h}$. The EPCs were treated with or without icariin $(1 \mu \mathrm{M})$ under high glucose condition for $4 \mathrm{~h}$ in the migration assay, for $8 \mathrm{~h}$ in Matrigel tube formation assay, and for $30 \mathrm{~min}$ in the measurement of NO production at room temperature. In the western blot analysis, the cells were stimulated with or without icariin $(1 \mu \mathrm{M})$ under a high glucose condition for $30 \mathrm{~min}$. The animal protocol in the present study was approved by the Institutional Animal Care and Use Committee, the Animal Care and Use Committee of Wuhan University (permit no. WDRM20161204).

Cell proliferation assay. Cell proliferation was assessed using a CCK-8 kit (Dojindo Molecular Technologies, Inc.). In each well of a 96-well plate, 5,000 EPCs were seeded and cultured for $12 \mathrm{~h}$ at $37^{\circ} \mathrm{C}$ in an atmosphere containing $95 \%$ air and $5 \% \mathrm{CO}_{2}$. After synchronization in EBM-2 with $0.1 \%$ FBS for $12 \mathrm{~h}$, the EPCs were treated with icariin at three different concentrations $(0.01,0.1$ or $1 \mu \mathrm{M})$ for $24 \mathrm{~h}$ at $37^{\circ} \mathrm{C}(20)$. Thereafter, a total of $20 \mu \mathrm{l}$ Cell Counting Kit-8 (CCK-8) reagent was added to each well and the cells were incubated at $37^{\circ} \mathrm{C}$ for a further $4 \mathrm{~h}$, The absorbance at $450 \mathrm{~nm}$ was subsequently measured. The results are expressed as the fold change of the optical density value divided by that of the control group.
Cell migration assay. To evaluate the migratory ability of EPCs, a Transwell chamber assay (Corning, Inc.) was performed. Briefly, EPCs were seeded at a density of $5 \times 10^{4}$ cells/well in the upper chamber with serum-free EBM-2 and different stimulation conditions, and the lower chamber was filled with serum-free EBM-2 containing stromal cell-derived factor 1a (SDF-1a; $100 \mathrm{ng} / \mathrm{ml}$ ). After incubation for $4 \mathrm{~h}$ at $37^{\circ} \mathrm{C}$, the cells on the top of the filter were removed, and the migrated cells on the bottom of the filter were fixed in $95 \%$ alcohol for $30 \mathrm{~min}$ and stained with $0.1 \%$ crystal violet for $10 \mathrm{~min}$ at room temperature. Then, the cells on the filter were counted manually in at least three random selected high-power fields (magnification, $\mathrm{x} 100$ ) in each well under a light microscope (Olympus Corporation).

Matrigel tube formation assay. A 24-well culture plate was coated with Matrigel (BD Biosciences), which was allowed to solidify for $30 \mathrm{~min}$ at $37^{\circ} \mathrm{C}$. EPCs $\left(5 \times 10^{4} /\right.$ well $)$ were seeded and incubated at $37^{\circ} \mathrm{C}$ for $8 \mathrm{~h}$. Tube formation was defined as a structure exhibiting a length four times its width. The total length of the tube formation was measured in three random fields (magnification, x100; Olympus Corporation) per group using Adobe Photoshop CS5 software (Adobe Systems, Inc.) (21).

Measurement of NO production. NO production was measured in culture medium with a total NO assay kit (cat. no. S0023; Beyotime Institute of Biotechnology). Briefly, EPCs (density, $1 \times 10^{4} / \mathrm{ml}$ ) were plated on dishes and exposed to various treatments. Then, the supernatants were collected following centrifugation $(140 \mathrm{x} \mathrm{g} ; 10 \mathrm{~min})$ at room temperature and analyzed according to the manufacturer's protocol. The total NO production of EPCs was determined by measuring the concentrations of nitrate and nitrite using the Griess method, and was normalized to standards in the total NO assay kit.

Western blot assay. Cells were lysed in a RIPA lysis buffer according to the manufacturer's protocol (BioVision, Inc.). Protein concentrations were determined by a bicinchoninic acid protein assay (Beyotime Institute of Biotechnology). Proteins samples $(4.5 \mu \mathrm{g} / \mu \mathrm{l} ; 20 \mu \mathrm{l}$ per lane) were separated using $10 \%$ SDS-PAGE and transferred onto PVDF membranes. For western blot analysis, the PVDF membranes were blocked at room temperature. with $5 \%$ non-fat dried milk that was dissolved in Tris-buffered saline containing $0.1 \%$ tween-20 for $90 \mathrm{~min}$ and probed with antibodies $(1: 1,000)$ against phosphorylated (p)-p38 (cat. no. sc-7973; Santa Cruz Biotechnology, Inc.), p38 (cat. no. ab7952; Abcam), protein-CREB (cat. no. 11273; Signalway Antibody LLC), CREB (cat. no. 9197; Cell Signaling Technology, Inc.), p-Akt (cat. no. 4060; Cell Signaling Technology, Inc.), Akt (cat. no. 21054; Signalway Antibody LLC), p-eNOS (cat. no. 9574; Cell Signaling Technology, Inc.), eNOS (cat. no. 21170; Signalway Antibody LLC) and GAPDH (cat. no. sc-365062; Santa Cruz Biotechnology, Inc.) overnight at $4^{\circ} \mathrm{C}$. After washing three times, the membranes were incubated with peroxidase-conjugated secondary antibodies (Goat Anti Rabbit IgG/HRP; 1:50,000; cat. no. 31460; Pierce; Thermo Fisher Scientific, Inc.; Goat Anti Mouse IgG/HRP; 1:50,000; cat. no. 31430; Pierce; Thermo Fisher Scientific, 
A

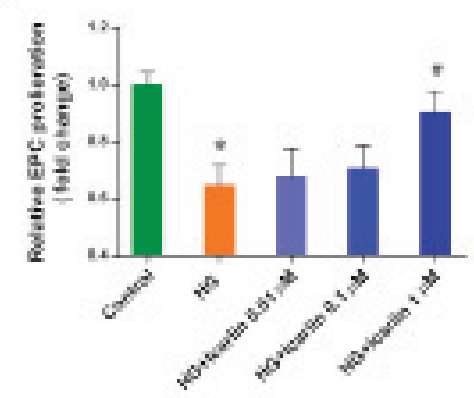

D

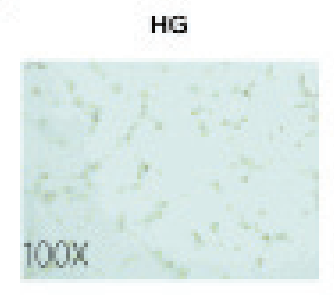

B

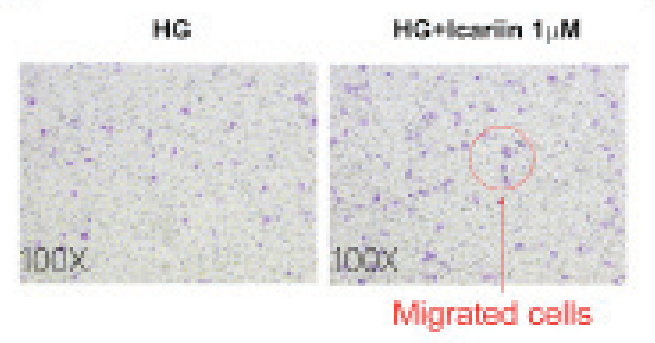

C

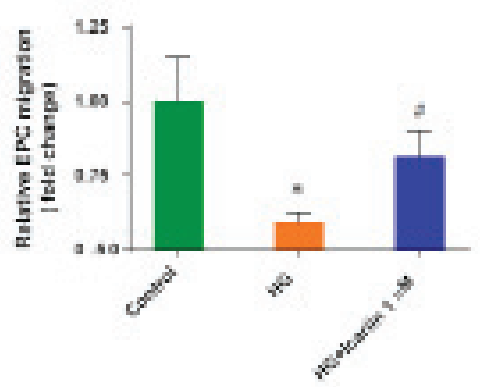

Figure 1. Icariin rescues the EPC dysfunction induced by HG. (A) EPCs were treated with various concentrations of icariin for 24 h in HG conditions. Cell proliferation was determined by a Cell Counting Kit- 8 assay. (B) EPCs were treated with or without $1 \mu \mathrm{M}$ icariin in Transwell plates for $4 \mathrm{~h}$. The migrated cells were counted under an optical microscope. (C) The relative levels of EPC migration. (D) EPCs cultured on a layer of Matrigel were treated with or without $1 \mu \mathrm{M}$ icariin. The total length of the tube formation was measured in three random fields. for each group. (E) The relative levels of EPC tube formation.Data are presented as the mean $\pm \mathrm{SD}$ of three individual experiments. $\mathrm{P}<0.05$ vs. Control group, ${ }^{\#} \mathrm{P}<0.05$ vs. HG group. EPC, endothelial progenitor cell; HG, high glucose.

Inc.) for $1 \mathrm{~h}$ at room temperature, and enhanced chemiluminescence (Thermo Fisher Scientific, Inc.) was performed. The autoradiographs were scanned using Adobe Photoshop CS5 software, and the protein ratios were calculated (22).

Statistical analysis. The experimental data are presented as the mean \pm SD. One-way analysis of variance followed by Bonferroni post hoc test was used for comparisons between continuous variables. All statistical analyses were performed using SPSS 19.0 for Windows (IBM Corp.). $\mathrm{P}<0.05$ was considered to indicate a statistically significant difference.

\section{Results}

Icariin attenuates the EPC dysfunction induced by $H G$. High glucose, which is a risk factor for CAD (23), significantly impaired EPC proliferation, migration and tube formation (Fig. 1). Icariin, a flavonoid extracted from genus Epimedium, exhibits various pharmacological activities (24). The differences between the HG group and icariin group were analyzed to evaluate the hypothesis that icariin could attenuate the impairment of EPC function induced by HG. Icariin had no notable effects on EPC viability (data not shown). Treatment with icariin ameliorated the inhibition of EPC proliferation in $\mathrm{HG}$ conditions in a dose-dependent manner in vitro, with maximal improvement observed following treatment with $1 \mu \mathrm{M}$ icariin (Fold change: $0.64 \pm 0.07 ; \mathrm{P}=0.0019 \mathrm{HG}$ group vs. control group; Fold change: $0.90 \pm 0.07, \mathrm{P}=0.01241 \mu \mathrm{M}$ icariin group vs. HG group; Fig. 1A). Additionally, $1 \mu \mathrm{M}$ icariin treatment significantly increased $\mathrm{HG}$-impaired EPC migration toward SDF-1a (Fold change: $0.59 \pm 0.03 ; \mathrm{P}=0.0100 \mathrm{HG}$ group vs. control group; Fold change: $0.81 \pm 0.08, \mathrm{P}=0.01481 \mu \mathrm{M}$ icariin group vs. HG group; Fig. 1B and C). Furthermore, icariin improved the in vitro tube-structure formation ability of EPCs in HG-stimulated conditions (Fold change: 0.52 \pm 0.06 ; $\mathrm{P}=0.0070 \mathrm{HG}$ group vs. control group; Fold change: $0.82 \pm 0.03$, $\mathrm{P}=0.0214 ; 1 \mu \mathrm{M}$ icariin group vs. HG group; Fig. 1D and $\mathrm{E})$.

Icariin inhibits the HG-induced activation of $p 38$ and CREB. p38 and its downstream target CREB have been reported to play a critical role in EPC downregulation induced by HG (25). Consistent with this previous study, increased p38 and CREB phosphorylation levels were observed in EPCs cultured in $25 \mathrm{mM}$ glucose for 3 days. These effects were significantly inhibited by icariin ( $1 \mu \mathrm{M}, 30 \mathrm{~min})$, and the treatments did not notably alter total p38 and CREB expression levels (p38 phosphorylation: Fold change: $2.38 \pm 0.17$; $\mathrm{P}=0.0005$ HG group vs. control group; Fold change: $1.84 \pm 0.21 ; \mathrm{P}=0.0238$ icariin group vs. HG group; CREB phosphorylation: Fold change: $3.04 \pm 0.22 ; \mathrm{P}=0.0002 \mathrm{HG}$ group vs. control group; Fold change: $2.24 \pm 0.15, \mathrm{P}=0.0068$ icariin group vs. HG group; Fig. 2).

Icariin activates Akt and $\mathrm{NOS}$, and promotes $\mathrm{NO}$ production in $H G$-treated EPCs. It has been reported that the inhibitory effects of $\mathrm{HG}$ on Akt and eNOS phosphorylation are involved in HG-induced EPC dysfunction (11). The effects of icariin on Akt and eNOS phosphorylation were determined via western blot analysis. Icariin treatment increased significantly Akt and eNOS phosphorylation compared with HG treatment only (Akt phosphorylation: Fold change: $0.29 \pm 0.07 ; \mathrm{P}=0.0016 \mathrm{HG}$ group vs. control group; Fold change: $0.64 \pm 0.08 ; \mathrm{P}=0.0047$ icariin group vs. HG group; eNOS phosphorylation: Fold 
A
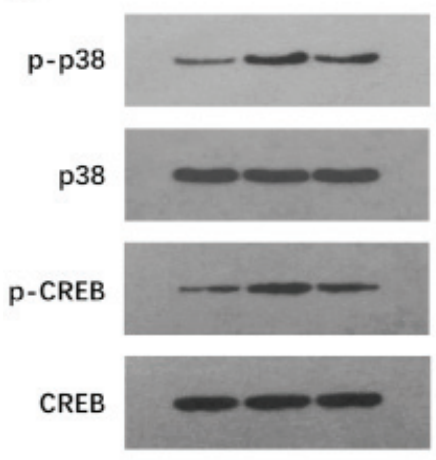

GADPH

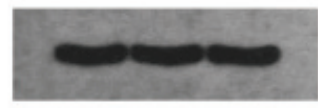

B
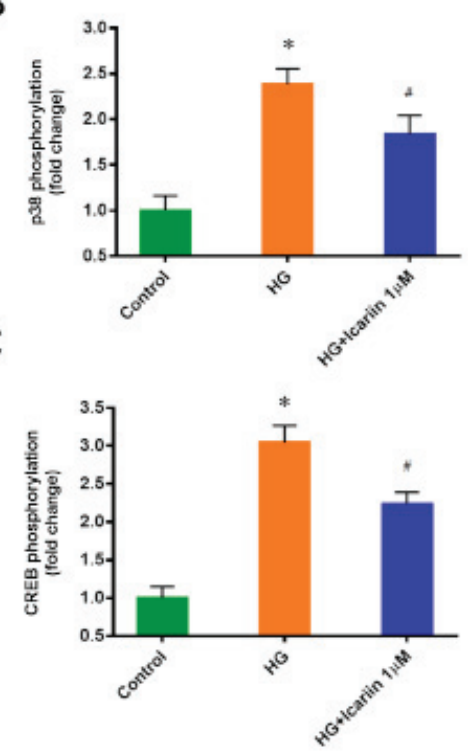

Figure 2. Icariin inhibits the HG-induced phosphorylation of p38 and CREB in EPCs. (A) EPCs cultured in 5.5 (Control) or 25 mM glucose (HG) were treated with or without $1 \mu \mathrm{M}$ icariin for $30 \mathrm{~min}$. Levels of p-p38, total p38, p-CREB and total CREB were determined via western blot analysis. (B) Quantitative results of the phosphorylated levels of p38. (C) Quantitative results of the phosphorylated levels of CREB. Data are presented as the mean \pm SD; $n=3 /$ group. ${ }^{*} \mathrm{P}<0.05$ vs. Control group, ${ }^{\#} \mathrm{P}<0.05$ vs. HG group. CREB, cAMP response element binding protein; EPC, endothelial progenitor cell; HG, high glucose; p-, phosphorylated.

A

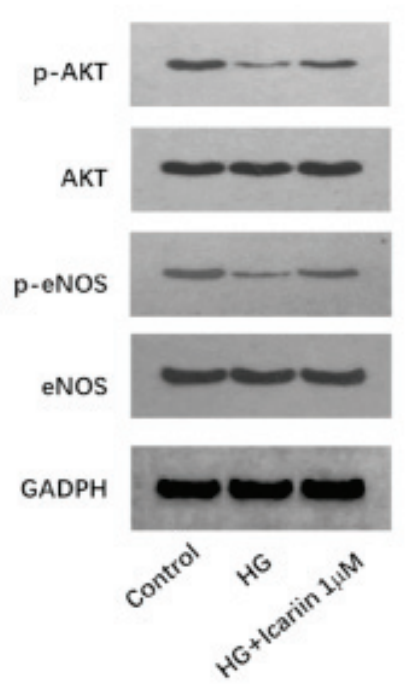

B

C

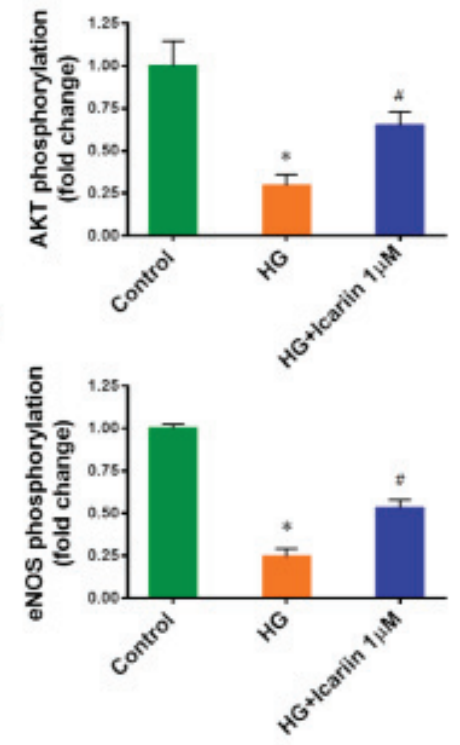

D

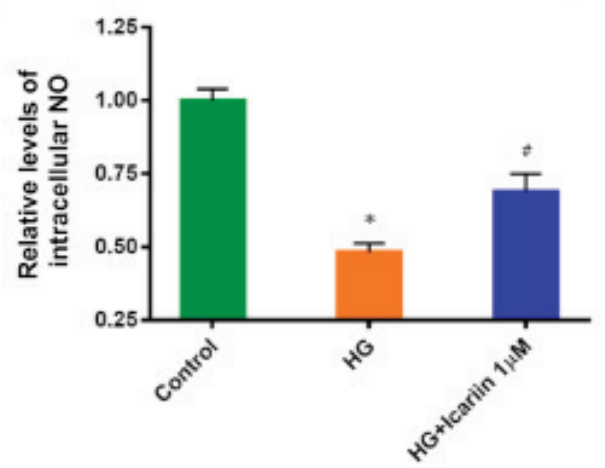

Figure 3. Icariin induces Akt and eNOS phosphorylation, and NO production in HG-treated EPCs.(A) EPCs were cultured in 5.5 (Control) or 25 mM glucose (HG) for 3 days with or without treatment with $1 \mu \mathrm{M}$ icariin for $30 \mathrm{~min}$. Levels of p-and total Akt and eNOS were determined via western blot analysis. (B) Quantitative results of the phosphorylated levels of Akt (C) Quantitative results of the phosphorylated levels of eNOS (D) EPCs were treated with or without $1 \square \mathrm{M}$ icariin for $3 \mathrm{~h}$. The relative levels of intracellular NO were determined by the concentrations of nitrate and nitrite. Data are presented as the mean \pm SD; $\mathrm{n}=3$ /group. ${ }^{*} \mathrm{P}<0.05$ vs. Control group, ${ }^{\sharp} \mathrm{P}<0.05$ vs. HG group. eNOS, endothelial nitric oxide synthase; EPC, endothelial progenitor cell; HG, high glucose; NO, nitric oxide; p-, phosphorylated. 


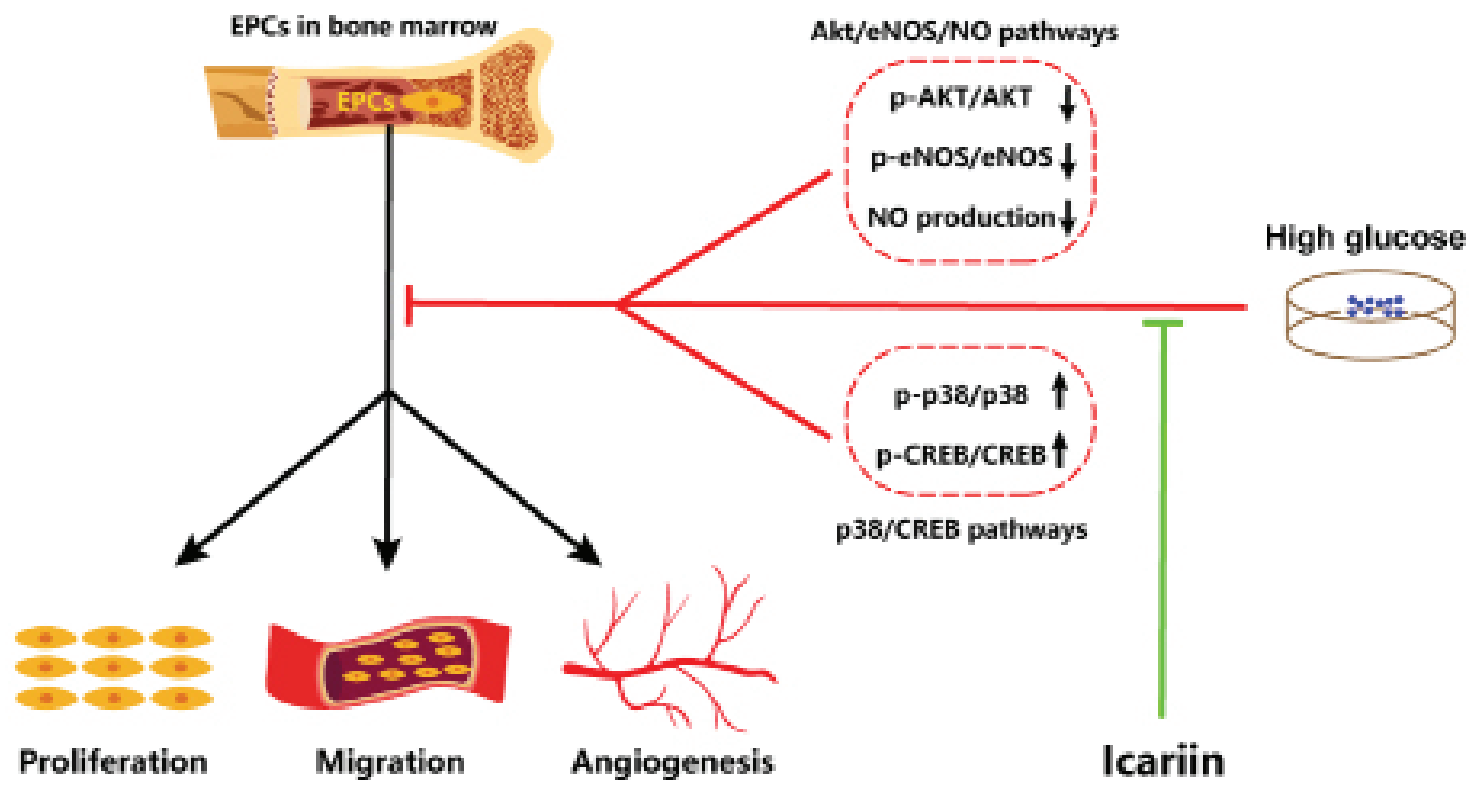

Figure 4. Schematic of the potential role and mechanisms of icariin in HG-induced EPC dysfunction. Icariin can inhibit the activation of the p38/CREB signaling pathway induced by HG in EPCs, and activate the Akt/eNOS/NO signaling pathway that is inhibited by HG in EPCs. It is proposed that via these mechanisms, icariin attenuates HG-induced EPC dysfunction. CREB, cAMP response element binding protein; eNOS, endothelial nitric oxide synthase; EPC, endothelial progenitor cell; HG, high glucose; NO, nitric oxide; p-, phosphorylated.

change: $0.24 \pm 0.05 ; \mathrm{P}<0.0001 \mathrm{HG}$ group vs. control group; Fold change: $0.53 \pm 0.05, \mathrm{P}=0.0019$ icariin group vs. $\mathrm{HG}$ group; Fig. 3A-C). Furthermore, icariin significantly attenuated the HG-induced inhibition of NO production (Fold change: $0.48 \pm 0.03 ; \mathrm{P}<0.0001 \mathrm{HG}$ group vs. control group; Fold change: $0.69 \pm 0.06 ; \mathrm{P}=0.0064$ icariin group vs. HG group; Fig. 3D).

\section{Discussion}

The present study demonstrated that icariin could ameliorate the inhibition of EPC proliferation, migration and tube formation induced by HG. Additionally, icariin significantly reduced the activation of the p38/CREB pathway and stimulated the Akt/eNOS/NO pathway in EPCs treated with HG. These results indicated potential mechanisms underlying the protective effects of icariin on EPCs, and suggested that icariin may be a useful agent for improving EPC function in a HG microenvironment.

Previous studies reported that icariin exerts endothelial protection effects $(17,26)$. Icariin stimulated human umbilical vein endothelial cell proliferation, migration (27) and $\mathrm{NO}$ release (28). Icariin also delayed homocysteine-induced senescence (27) and inhibited oxidation-induced apoptosis (29). However, the effects of icariin on EPC function remain unclear. Numerous clinical trials are attempting to elucidate the therapeutic effects of EPCs in cardiovascular diseases, but the CAD risk factors that may reduce the number and biological activity of EPC limit the success of EPC transplantation in patients $(6,30)$. Therefore, this study focused mainly on the effects of icariin on EPCs under HG conditions, which is one of the major CAD risk factors (23). HG has been shown to adversely affect the number and function of EPCs, leading to reductions in the angiogenic abilities of EPCs (31). Consistent with the current study, the present data demonstrated that incubation with HG induces adverse effects on EPC function.
Of note, the present findings showed that icariin treatment attenuates HG-induced EPC dysfunction.

Several mechanisms may be involved in the HG-induced reduction in EPC number, and impairment in EPC proliferative and migratory abilities. p38 MAPK and its downstream target CREB have been shown to decrease the number and proliferation of EPCs (25). HG induced the p38-dependent phosphorylation of CREB, thereby inhibiting proliferation (25). As icariin has been reported to modulate $\mathrm{p} 38$ phosphorylation in other cell types $(32,33)$, this may be a potential effector signaling mechanism via which icariin attenuated the impaired proliferation of HG-treated EPCs. In the present study, p38 and CREB were demonstrated to be phosphorylated under high glucose conditions, and icariin could reduce these effects.

Another important mechanism involved with HG-induced impairments in EPC migration is the inhibition of $\mathrm{PI} 3 \mathrm{~K} / \mathrm{Akt} / \mathrm{eNOS}$ activation and NO production (11), suggesting that the effects of icariin on Akt/eNOS may ameliorate this dysfunction. Icariin is also known to stimulate angiogenesis by activating PI3K/Akt/eNOS-dependent signaling pathways in human endothelial cells (28). Akt/eNOS activation is also known to increase NO activation (34), and $\mathrm{NO}$ is known to regulate the migration of EPCs (35). The restored migration induced by icariin may be due to upregulated Akt/eNOS phosphorylation and NO production. In the present study, it was demonstrated that high glucose could inhibit the phosphorylation of Akt/eNOS and the production of NO, and these effects were significantly attenuated by icariin.

There are certain limitations to the present study. Only in vitro experiments were performed to show that icariin could reduce HG-induced EPC dysfunction. EPC function in HG microenvironments was only evaluated in vitro, while the damage produced by HG in humans is observed after several years in vivo. Although the present study may provide a certain degree of insight into the mechanisms involved in vivo, further 
study in vivo is required to clarify the exact mechanisms. Additionally, gene silencing technology could be employed to further demonstrate the exact role of the p38/CREB and Akt/eNOS signaling pathways in the effects induced by icariin.

Collectively, the results of the present study demonstrated that icariin can attenuate HG-induced EPC dysfunction in vitro, including improving proliferation, migration and tube formation. Furthermore, the possible molecular mechanisms involved were identified as the inhibited activation of the p38/CREB signaling pathway and the promotion of the Akt/eNOS/NO signaling pathway (Fig. 4). Therefore, icariin may be a potentially promising tool for protecting EPC function against $\mathrm{HG}$.

\section{Acknowledgements}

Not applicable.

\section{Funding}

The present study was supported by the National Natural Science Foundation of China (grant no. 81600226).

\section{Availability of data and materials}

The datasets used and/or analyzed during the current study are available from the corresponding author on reasonable request.

\section{Authors' contributions}

HJ designed and directed the experiments. SC, ZW and HZ performed the experiments. SC, ZW, HB and DH collected and analyzed the experimental data. SC and HJ wrote the manuscript. $\mathrm{HZ}$ and $\mathrm{HB}$ investigated the relevant literature and revised the manuscript. All authors read and approved the final manuscript.

\section{Ethics approval and consent to participate}

The present study was approved by Institutional Animal Care and Use Committee, the Animal Care and Use Committee of Wuhan University (permit no. WDRM20161204).

\section{Patient consent for publication}

Not applicable.

\section{Competing interests}

The authors declare that they have no competing interests.

\section{References}

1. Asahara T, Masuda H, Takahashi T, Kalka C, Pastore C, Silver M, Kearne M, Magner M and Isner JM: Bone marrow origin of endothelial progenitor cells responsible for postnatal vasculogenesis in physiological and pathological neovascularization. Circ Res 85: 221-228, 1999.

2. Jin P, Li T, Li X, Shen X and Zhao Y: Suppression of oxidative stress in endothelial progenitor cells promotes angiogenesis and improves cardiac function following myocardial infarction in diabetic mice. Exp Ther Med 11: 2163-2170, 2016.
3. Jaipersad AS, Lip GY, Silverman S and Shantsila E: The role of monocytes in angiogenesis and atherosclerosis. J Am Coll Cardiol 63: 1-11, 2014

4. Odent Grigorescu G, Preda MB, Radu E, Rosca AM, Tutuianu R, Mitroi DN, Simionescu M and Burlacu A: Combinatorial approach for improving the outcome of angiogenic therapy in ischemic tissues. Biomaterials 60: 72-81, 2015.

5. Shantsila E, Watson T and Lip GY: Endothelial progenitor cells in cardiovascular disorders. J Am Coll Cardiol 49: 741-752, 2007.

6. Vasa M, Fichtlscherer S, Aicher A, Adler K, Urbich C, Martin H, Zeiher AM and Dimmeler S: Number and migratory activity of circulating endothelial progenitor cells inversely correlate with risk factors for coronary artery disease. Circ Res 89: E1-E7, 2001.

7. Fadini GP, Sartore S, Albiero M,Baesso I, Murphy E, Menegolo M, Grego F, Vigili de Kreutzenberg S, Tiengo A, Agostini C, et al: Number and function of endothelial progenitor cells as a marker of severity for diabetic vasculopathy. Arterioscler Thromb Vasc Biol 26: 2140-2146, 2006.

8. Fadini GP, Miorin M, Facco M, Bonamico S, Baesso I, Grego F, Menegolo M, de Kreutzenberg SV, Tiengo A, Agostini C, et al: Circulating endothelial progenitor cells are reduced in peripheral vascular complications of type 2 diabetes mellitus. J Am Coll Cardiol 45: 1449-1457, 2005.

9. Tsukada S, Masuda H, Jung SY, Yun J, Kang S, Kim DY, Park JH, Ji ST, Kwon SM and Asahara T: Impaired development and dysfunction of endothelial progenitor cells in type 2 diabetic mice. Diabetes Metab 43: 154-162, 2017.

10. Chang J, Li Y, Huang Y, Lam KS, Hoo RL, Wong WT, Cheng KK, Wang Y, Vanhoutte PM and Xu A: Adiponectin prevents diabetic premature senescence of endothelial progenitor cells and promotes endothelial repair by suppressing the p38 MAP kinase/p16INK4A signaling pathway. Diabetes 59: 2949-2959, 2010.

11. Sun N, Wang H and Wang L: Vaspin alleviates dysfunction of endothelial progenitor cells induced by high glucose via PI3K/Akt/eNOS pathway. Int J Clin Exp Pathol 8: 482-489, 2015.

12. Chen YH, Lin SJ, Lin FY, Wu TC, Tsao CR, Huang PH, Liu PL, Chen YL and Chen JW: High glucose impairs early and late endothelial progenitor cells by modifying nitric oxide-related but not oxidative stress-mediated mechanisms. Diabetes 56: 1559-1568, 2007.

13. Shen R and Wang JH: The effect of icariin on immunity and its potential application. Am J Clin Exp Immunol 7: 50-56, 2018.

14. Jin J, Wang H, Hua X, Chen D, Huang C and Chen Z: An outline for the pharmacological effect of icariin in the nervous system. Eur J Pharmacol 842: 20-32, 2019.

15. Wang Z, Wang D, Yang D, Zhen W, Zhang J and Peng S: The effect of icariin on bone metabolism and its potential clinical application. Osteoporos Int 29: 535-544, 2018.

16. Qian ZQ, Wang YW, Li YL, Li YQ, Ling-Zhu and Yang DL: Icariin prevents hypertension-induced cardiomyocyte apoptosis through the mitochondrial apoptotic pathway. Biomed Pharmacother 88: 823-831, 2017.

17. Xu HB and Huang ZQ: Icariin enhances endothelial nitric-oxide synthase expression on human endothelial cells in vitro. Vascul Pharmacol 47: 18-24, 2007.

18. Song E, Lu CW, Fang LJ and Yang W: Culture and identification of endothelial progenitor cells from human umbilical cord blood. Int J Ophthalmol 3: 49-53, 2010.

19. Hamed S, Brenner B, Abassi Z, Aharon A, Daoud D and Roguin A: Hyperglycemia and oxidized-LDL exert a deleterious effect on endothelial progenitor cell migration in type 2 diabetes mellitus. Thromb Res 126: 166-174, 2010.

20. Koizumi H, Yu J, Hashimoto R, Ouchi Y and Okabe T: Involvement of androgen receptor in nitric oxide production induced by icariin in human umbilical vein endothelial cells. FEBS Lett 584: 2440-2444, 2010.

21. Ma FX, Chen F, Ren Q and Han ZC: Lovastatin restores the function of endothelial progenitor cells damaged by oxLDL. Acta Pharmacol Sin 30: 545-552, 2009.

22. Cheng L, Xu J, Qian YY, Pan HY, Yang H, Shao MY, Cheng R and Hu T: Interaction between mDial and ROCK in Rho-induced migration and adhesion of human dental pulp cells. Int Endod J 50: 15-23, 2017.

23. Ross S, Gerstein HC, Eikelboom J, Anand SS, Yusuf S and Paré G: Mendelian randomization analysis supports the causal role of dysglycaemia and diabetes in the risk of coronary artery disease. Eur Heart J 36: 1454-1462, 2015.

24. Li C, Li Q, Mei Q and Lu T: Pharmacological effects and pharmacokinetic properties of icariin, the major bioactive component in Herba Epimedii. Life Sci 126: 57-68, 2015. 
25. Seeger FH, Haendeler J, Walter DH, Rochwalsky U, Reinhold J, Urbich C, Rössig L, Corbaz A, Chvatchko Y, Zeiher AM, et al: p38 mitogen-activated protein kinase downregulates endothelial progenitor cells. Circulation 111: 1184-1191, 2005.

26. Xiao HB, Liu ZK, Lu XY, Deng CN and Luo ZF: Icariin regulates PRMT/ADMA/DDAH pathway to improve endothelial function. Pharmacological reports: PR 67: 1147-1154, 2015.

27. Xiao-Hong D, Chang-Qin X, Jian-Hua H, Wen-Jiang Z and Bing S: Icariin delays homocysteine-induced endothelial cellular senescence involving activation of the PI3K/AKT-eNOS signaling pathway. Pharm Biol 51: 433-440, 2013.

28. Chung BH,Kim JD,Kim CK,KimJH, Won MH,LeeHS, Dong MS, Ha KS, Kwon YG and Kim YM: Icariin stimulates angiogenesis by activating the MEK/ERK- and PI3K/Akt/eNOS-dependent signal pathways in human endothelial cells. Biochem Biophys Res Commun 376: 404-408, 2008.

29. Song YH, Cai H, Zhao ZM, Chang WJ, Gu N, Cao SP and Wu ML: Icariin attenuated oxidative stress induced-cardiac apoptosis by mitochondria protection and ERK activation. Biomed Pharmacother 83: 1089-1094, 2016.

30. Wang HY, Gao PJ, Ji KD, Shen WF, Fan CL, Lu L and Zhu DL: Circulating endothelial progenitor cells, C-reactive protein and severity of coronary stenosis in Chinese patients with coronary artery disease. Hypertension Research: Official Journal of the Japanese Society of Hypertension 30: 133-141, 2007.
31. Huang PH, Chen JW, Lin CP, Chen YH, Wang CH, Leu HB and Lin SJ: Far infra-red therapy promotes ischemia-induced angiogenesis in diabetic mice and restores high glucose-suppressed endothelial progenitor cell functions. Cardiovasc Diabetol 11: 99, 2012.

32. Ding L, Liang XG, Hu Y, Zhu DY and Lou YJ: Involvement of p38MAPK and reactive oxygen species in icariin-induced cardiomyocyte differentiation of murine embryonic stem cells in vitro. Stem Cells Dev 17: 751-760, 2008.

33. Qin S, Zhou W, Liu S, Chen $\mathrm{P}$ and Wu H: Icariin stimulates the proliferation of rat bone mesenchymal stem cells via ERK and p38 MAPK signaling. Int J Clin Exp Med 8: 7125-7133, 2015.

34. Taguchi K, Hida M, Hasegawa M, Matsumoto T and Kobayashi T: Dietary polyphenol morin rescues endothelial dysfunction in a diabetic mouse model by activating the Akt/eNOS pathway. Mol Nutr Food Res 60: 580-588, 2016.

35. Hamed S, Brenner B and Roguin A: Nitric oxide: A key factor behind the dysfunctionality of endothelial progenitor cells in diabetes mellitus type-2. Cardiovasc Res 91: 9-15, 2011.

This work is licensed under a Creative Commons Attribution-NonCommercial-NoDerivatives 4.0 International (CC BY-NC-ND 4.0) License. 